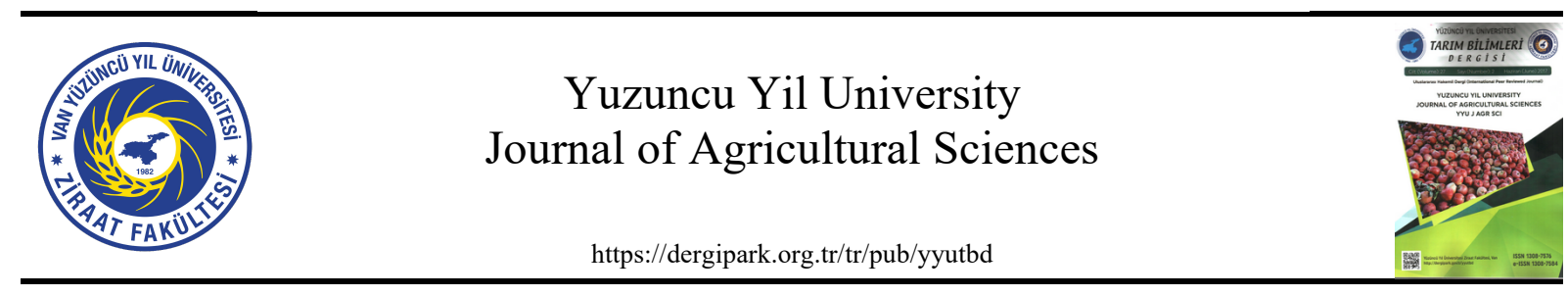

Research Article (Araștırma Makalesi)

\title{
Efficacy Detection of Low-Cost Hall Effect Sensor for a LabVIEW-Based Agricultural Gaussmeter
}

\author{
Abdullah BEYAZ ${ }^{* 1}$, Doğukan PARLAK ${ }^{2}$ \\ ${ }^{1}$ Ankara University, Faculty of Agriculture, Department of Agricultural Machinery and Technologies \\ Engineering, 06110 Diskapi/Ankara/TURKEY \\ ${ }^{2}$ Ankara University, Faculty of Agriculture, Department of Fisheries and Aquaculture Engineering, 06110
} Diskapi/Ankara/TURKEY

${ }^{1}$ https://orcid.org/0000-0002-7329-1318 ${ }^{2}$ https://orcid.org/0000-0003-2553-4677

*Corresponding author e-mail; abeyaz@ankara.edu.tr

\section{ArticleInfo}

Received: 03.05.2021

Accepted: 24.07.2021

Online Published: 15.09.2021

DOI: 10.29133 /yyutbd.932155

\section{Keywords}

Gaussmeter,

Hall effect sensor,

LabVIEW,

Magnetic field,

Microcontroller.

\begin{abstract}
Developing technology enables more accurate and efficient measurement with the help of low-cost sensors. Therefore, in this study, a gaussmeter that can be used for agricultural purposes was developed using a lowcost microcontroller development card. The developed low-cost gaussmeter includes an inexpensive magnetic field sensor, a microcontroller development card, and LabVIEW software. Magnetic field measurements, based on the optimization of the microcontroller-based gaussmeter, were developed with the HAL503 Hall Effect sensor with the help of LabVIEW software. A high regression was observed between the values obtained from the device and the results found from the calculations made using theoretical magnetic field formulas and the measured values. It was observed that it works with an average accuracy of $99.6 \%$ for 3 different thickness magnets. According to the developed measuring device results of 6,8 , and 10 magnets sizes, $\mathrm{R}^{2}$ values were evaluated as $99.8 \%$, $99.7 \%$, and $99.3 \%$, respectively.
\end{abstract}

\section{LabVIEW Tabanlı Tarımsal Amaçı bir Gaussmetre için Düşük Maliyetli Hall Etkisi Duyargasının Etkinlik Tespiti}

\section{Makale Bilgileri}

Geliş: 03.05.2021

Kabul: 24.07.2021

Online Yayınlanma: 15.09.2021

DOI: 10.29133 /yyutbd.932155

\author{
Anahtar Kelimeler \\ Gaussmetre, \\ Hall etkisi duyargası, \\ LabVIEW. \\ Manyetik alan, \\ Mikrodenetleyici,
}

Öz: Gelişen teknoloji düşük maliyetli duyargalar yardımıyla daha doğru ve verimli ölçüm yapılmasını sağlamaktadır. Bu nedenle bu çalışmada, düşük maliyetli tarımsal amaçlı kullanılabilecek bir gaussmetre geliştirilmiştir. Geliştirilen düşük maliyetli gaussmetre, bir manyetik alan duyargası, bir mikrodenetleyici geliştirme kartı ve LabVIEW yazılımından oluşmaktadır. Manyetik alan ölçümleri LabVIEW yazılımı yardımıyla HAL503 Hall Effect duyargası ile geliştirilen mikrodenetleyici tabanlı gaussmetrenin optimizasyonuna dayalı olarak yapılmıştır. Cihazdan elde edilen değerler ile teorik manyetik alan formülleri kullanılarak yapılan hesaplamalardan bulunan değerler arasında yüksek bir regresyon gözlenmiştir. HAL503 hall etkisi duyargası kullanılarak yapılan bu çalışmada, 3 farklı kalınlıktaki mıknatıs için cihazın ortalama \%99.6 hassasiyetle çalıştığ 1 görülmüştür. 6,8 ve 10 miknatıs boyutunda, geliştirilen ölçüm cihazı $\mathrm{R}^{2}$ değerleri sırasıyla \%99.8, \%99.7 ve \% 99.3 olarak hesaplanmıştır. 


\section{Introduction}

The first magnetometer was invented by Carl Friedrich Gauss in 1833 with the ability to measure magnetic density. There have been notable developments in the Hall Effect, which is still widely used for magnetic field measurements in the 19th century (Khan et al., 2017). Sensors used for magnetic field measurements play an important role in many areas. For example, space researches (Can and Topal, 2015), agricultural and aquaculture enhancement, water treatment (Lin and Yotvat, 1990), agricultural machinery, and military systems are well-known applications (Nowicki and Szewczyk, 2013; Nowicki and Szewczyk, 2019). Agricultural production and irrigation magnetic field studies provide important progress in agriculture sector.

Lin and Yotvat (1990) reported an increase in water efficiency in both crop and livestock production at magnetically treated water. In another study, Amaya et al. (1996) and Podlesny et al. (2004) showed the acceleration of plant growth, especially the seed germination and emergence rate, through optimal external electromagnetic fields. Podlesny et al. (2004) investigated and observed significant beneficial effects on germination, emergence, and seed yield by exposing the pod seeds to varying magnetic forces before planting. After the use of magnetic treatment, a more regular plant occurred and 2-3 days before the control process was observed. The magnetic field effect has also been found to be effective when consuming plants with nutrients. Some studies show that strawberries and tomatoes are increasingly flowering, early in life, and total fruit output by applying magnetic fields (Esitken and Turan, 2004; Danilov et al., 1993). Duarte Diaz et al. (1997) have observed an increase in the intake of food in magnetic processing. In the literature, the root growth of different plant species is influenced by magnetic field applications (Belyavskaya, 2001; Belyavskaya, 2004; Muraji et al., 1992; Muraji et al., 1998; Turker et al., 2007). Maize (Zea mays) root growth increase was shown by Muraji et al. (1992) in the form of exposure to $5 \mathrm{mT}$ magnetically grown seedlings at an alternative frequency of 40-160 Hz. Also magnetic field application improve yield and plant growth in cucumber, as well as an iron chelate (Ahmadi et al., 2020). Additionally, the magnetic field is known to reduce stress in seedlings caused by heat. For 40 minutes, the effect of heat stress on cress seedlings (Lepidium sativum) was reduced by exposure to a highly low-frequency magnetic field $(50 \mathrm{~Hz}, 100 \mathrm{~T})$.

Hall effect refers to the phenomenon in which a potential difference develops in a conductor that carries current in a magnetic field. This fact was discovered by Edwin Hall in 1879 (Hall, 1879). It is believed that gaussmeter and electronic integrated flux meters are the most used devices for measuring magnetic flux density (Seely, 1997). To ensure the proper use of magnetic measuring instruments, it is necessary to understand the application methods of these tools (Murphy, 1999). Measuring the magnetic field using the Hall Effect sensors is only one of these application methods (Blagojevic et al., 2004; Logofatu et al., 1997), and gaussmeter are used for this purpose. The use of gaussmeter's for magnetic parameters and properties of materials is a result of particle movement in the electric field. Besides, different types of electricity in AC and DC can be measured using an industrial gaussmeter with a Halleffect sensor. When the sensor is near a magnetic field, it creates voltage differences according to the strength of the magnetic field. However, they are costly as industrial measuring instruments. Hall sensors, AMR sensors, GMR - STD sensors, FLUXGATE sensors, and some other devices use magnetic field measurements (Ripka and Janosek, 2010). Also, different development cards such as Arduino, ARM, Raspberry Pi can be used for this purpose (Khan et al., 2017). In the literature, Prasad et al. (2014) stated that a low-cost development card-based device can be used to conduct various experiments on magnetism in the physics laboratories. There are many Hall generators known today (Randjelovic et al., 1999; Popovic, 1991). However, the noise impact of hall sensors limits their use (Popovic et al., 2001). The hall effect plane is important in magnetic fields measured using the Hall sensor (Morvic and Betko, 2005; Goldberg and Davis, 1954; Schott et al., 2000). The sensor used in this study is the HAL503 linear Hall Effect sensor. The principle of operation of the sensor used is that when the current is kept constant, the voltage changes linearly according to the magnetic field (Badaroglu et al., 2008). Magnetic sensors are solid-state devices that are becoming more and more popular because they can be used in many different types of applications such as sensing position, velocity, or directional movement (Khan et al., 2017).

In this research, considering the literature, the efficacy of a microcontroller and LabVIEW-based gaussmeter has been studied with the help of HAL503 magnetic field sensor that works based on 
magnetic field theory for effectiveness detection because of the future low-cost magnetic field applications in agriculture.

\section{Material and Method}

\subsection{Material}

The main subject of the adjustment is the development of an effective system in the LabVIEW environment that can measure the magnetic field values of three different thickness neodymium magnets in gauss and millitesla levels under controlled laboratory conditions with low-cost parts (Figure 1).

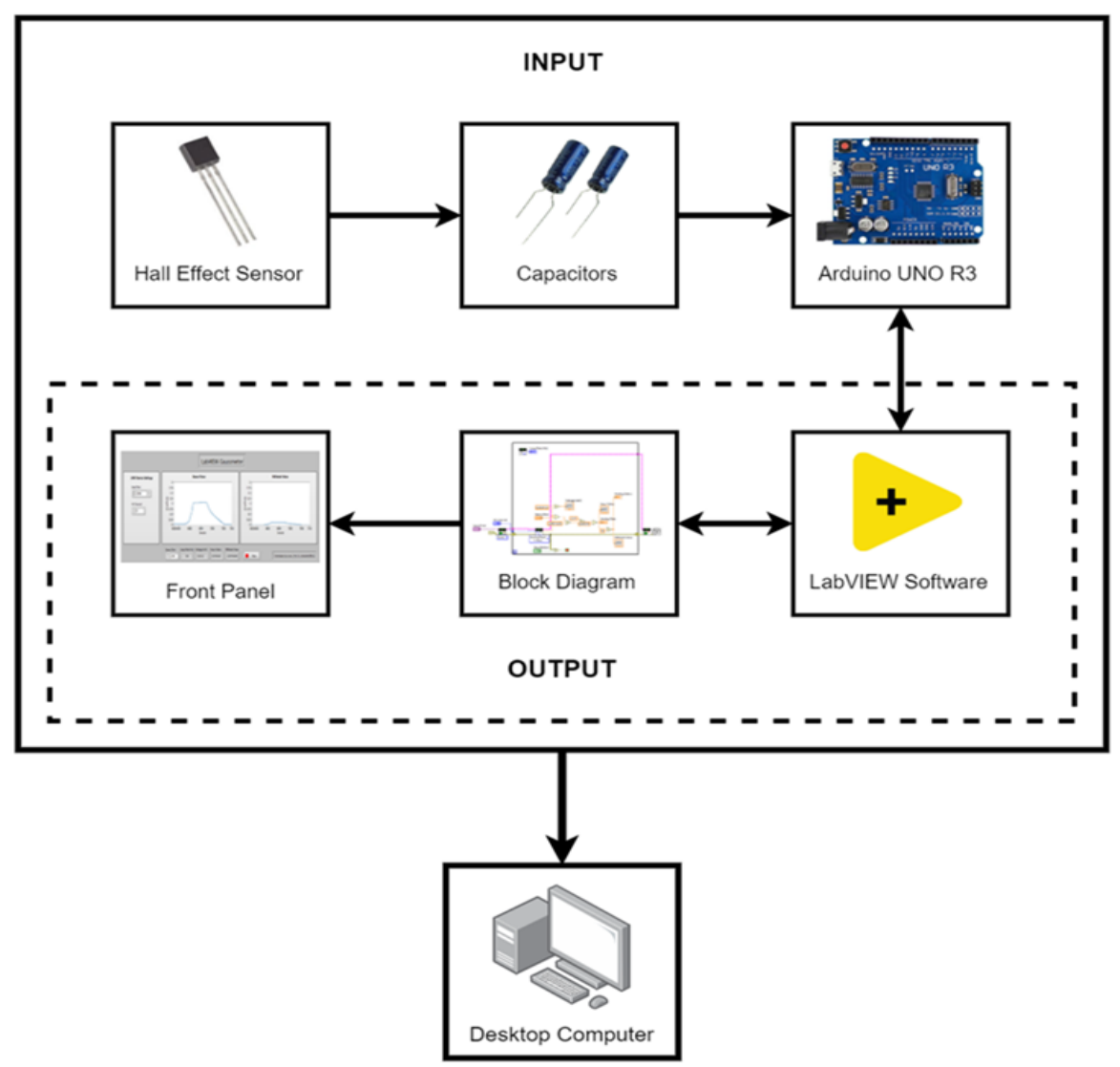

Figure 1. Flow chart of LabVIEW-based gaussmeter software.

For this purpose, the voltage of the HAL503 magnetic field sensor, which received the analog 0 pin signal of the Arduino UNO R3 microcontroller development card, is stabilized using two 16V $100 \mathrm{uF}$ capacitors (Figure 3 - 5). Arduino Uno R3 can be operated via USB and communicates with LabVIEW software via Serial Port (COM) (D'Ausilio, 2012). Sensor values obtained through Arduino matching LabVIEW software, that are calculated in the block diagram of the LabVIEW software and the signals processed in the graphics and measurement boxes created in the front panel $(66 \mathrm{~Hz})$ are given instantly (Figure 9 - 10). LabVIEW, which can interfere with the front panel and block diagram in these computer operations, can provide the user a comfortable reading on the front panel (Figure 1).

\subsubsection{Magnetic Field Generation}

The most powerful permanent magnets currently available are neodymium magnets, which were developed in 1982 by General Motors and Sumitomo Special Metals. Many applications of modern products that include powerful permanent magnets, such as motors in cordless drills, hard disk drives, and magnetic fasteners, have been taken over by them. Rare Earth magnets (also known as Neodymium 
magnets) are 5-7 times stronger than Ferrite magnets and are the most cost-effective. Higher values, from N35 to N52, indicate stronger magnets. The magnetic field was created by layering various thicknesses of N35 neodymium magnets (Table 1).

Table 1. Features of N35 neodymium magnets that are used in the application

\begin{tabular}{|c|c|c|c|c|c|c|c|c|c|}
\hline \multirow[t]{3}{*}{ Grade } & \multicolumn{2}{|c|}{ Residual magnetism } & \multicolumn{4}{|c|}{ Coercive and field strength } & \multirow{2}{*}{\multicolumn{2}{|c|}{$\frac{\text { Energy product }}{(\mathrm{BxH}) \max .)}$}} & \multirow{2}{*}{$\begin{array}{c}\text { Max. } \\
\text { operational } \\
\text { temp. }\end{array}$} \\
\hline & \multicolumn{2}{|c|}{$\mathrm{Br}$} & \multicolumn{2}{|c|}{$\mathrm{bHc}$} & \multicolumn{2}{|c|}{$\mathrm{iHc}$} & & & \\
\hline & Gauss(G) & $\begin{array}{l}\text { Tesla } \\
\text { (T) }\end{array}$ & $\mathrm{kOe}$ & $\mathrm{kA} / \mathrm{m}$ & $\mathrm{kOe}$ & $\mathrm{kA} / \mathrm{m}$ & MGOe & $\mathrm{kJ} / \mathrm{m}^{3}$ & ${ }^{\circ} \mathrm{C}$ \\
\hline N35 & $\begin{array}{l}11700- \\
12100\end{array}$ & $\begin{array}{l}1.17- \\
1.21\end{array}$ & $\begin{array}{l}10.8- \\
11.5\end{array}$ & $\begin{array}{l}860- \\
915\end{array}$ & $\geq 12$ & $\geq 955$ & $33-35$ & $263-279$ & $\leq 80$ \\
\hline
\end{tabular}

Br: Remanence, bHc: coercive field force, iHc: demagnetized field strength, BxH: maximum energy product, N35: Type of neodymium magnet.

Three different neodymium magnets group were used for the measurements. 6, 8, and 10 magnets which have $10 \mathrm{~mm}$ diameter and $3 \mathrm{~mm}$ thickness were used respectively (Figure 2). In this way, at different thickness levels, different magnetic fields were obtained from N35 neodymium magnets. Additionally, with the N35 neodymium magnets, three different magnetic fields created for 25 different distance levels change $1 \mathrm{~mm}$ between the measurements $10 \mathrm{~mm}$ to $35 \mathrm{~mm}$.

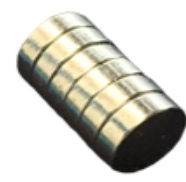

(a)

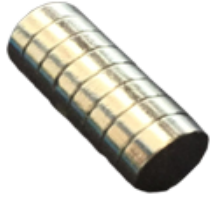

(b)

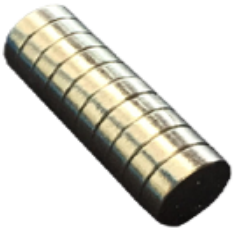

(c)

Figure 2. 6 neodymium magnets (a), 8 neodymium magnets (b) and 10 neodymium magnets(c).

Neodymium magnets are generally more powerful than normal magnets. However, neodymium magnets cost more due to the more expensive materials needed to manufacture them: they require a mixture of iron, neodymium, and boron to magnetize via exposure to a powerful magnetic field. Normal and neodymium magnets each have different benefits. Neodymium magnets are metal magnets, and they are colored in silver, like most other metals. The neodymium magnet is extremely strong, with magnetic strengths between N24 and N55, with N55 being the strongest manufactured.

\subsubsection{Arduino UNO R3}

There are a lot of different development boards in the markets. However, Arduino UNO R3 is the widely used one between them (Figure 3). It has enough capability and technical properties for this low-cost measurement device development process. The board is easily connected with LabVIEW software by using the LINX firmware. In this development process, an analog input of the board was used for getting the voltage values. Also, it was used for the measurement of gauss values. For this aim, the software was developed in the LabVIEW platform. 


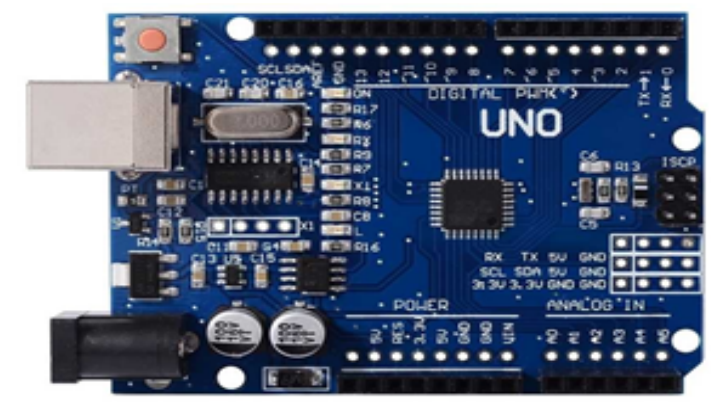

Figure 3. Arduino UNO R3 microcontroller board front view.

The Arduino development card uses an ATmega328 embedded microcontroller from Atmel, which has 6 analog inputs with 10-bit resolution, and a USB (Universal Serial Bus) connection.

\subsubsection{HAL503 Hall Effect Sensor}

The HAL503 is the sensor for the Hall effect that monitors very little magnetic density changes, very small changes in the Hall effect controls. HAL503 hall effect sensor contains the Vcc, ground, and Vdd terminals (Figure 4). They are magnetically driven mirrors for mechanical phenomena like motion sensors, gear tooth sensors, and detectors of proximity. As sensitive electromagnet monitoring systems, the performance of the system can be effectively measured by negligible loading of systems, while providing insulation from contaminated and noisy environments. Each integrated Hall Effect circuit comprises a Hall sensor element, the linear amplifier, and the output stage for the emitter follower. The Hall cell and amplifier in one chip minimizes problems with the processing of small analog signals. For most applications, three-pack styles deliver a magnetically optimized pack. The 'UA' packet suffix is an ultra-mini SIP three-pin.
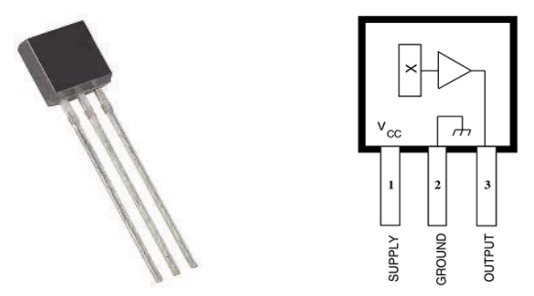

Figure 4. HAL503 Hall effect sensor and pinout.

For continuous operation, the sensor is evaluated within $-40^{\circ} \mathrm{C}$ to $+170^{\circ} \mathrm{C}$. It has a high sensitivity. It can function up to $10 \mathrm{kHz}$ and dynamic magnetic fields in static magnetic fields. Becoming suitable for multi-poles and rotational speed measurements, the HAL503 hall effect sensing sensors and operating range allow for this application. The HAL503 Hall Effect Sensor absolute maximum values can be seen in Table 2 .

Table 2. Absolute maximum ratings of HAL503 Hall Effect Sensor

\begin{tabular}{ll}
\hline Absolute Maximum Ratings & Specification \\
\hline Supply Voltage $(\mathrm{Vcc})$ & $3.8 \mathrm{~V}$ to $24 \mathrm{~V}$ \\
Magnetic Flux Density & B Unlimited \\
Operating Temperature Range $\left(\mathrm{T}_{\mathrm{A}}\right)$ & $-40^{\circ} \mathrm{C}$ to $+170^{\circ} \mathrm{C}$ \\
Switching Type & Latching \\
\hline
\end{tabular}




\subsubsection{Capacitors}

A capacitor is a component that stores potential energy in an electric field between the passive two-electrical terminal (Figure 5). The effect of a capacitor was called capacitance. While some capacitance exists between any two electrical conductors in proximity to a circuit, a capacitor is an electrical component that was designed to add capacitance to a circuit. The capacitor was initially known as a condenser (Anonymous, 2018). In this magnetic field measurement system, two capacitors (100 $\mu \mathrm{F}$ ) were used to control the current.

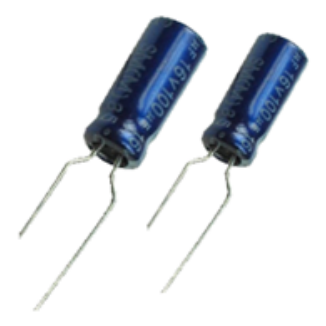

Figure 5. 16V $100 \mu \mathrm{F}$ capacitors.

In the research, the hall effect sensor's output was connected to the A0 pin of the Arduino, which communicates with the computer via a USB (Universal Serial Bus), and thus the voltage data sent to the Arduino was processed through the LabVIEW program (Figure 6-7).

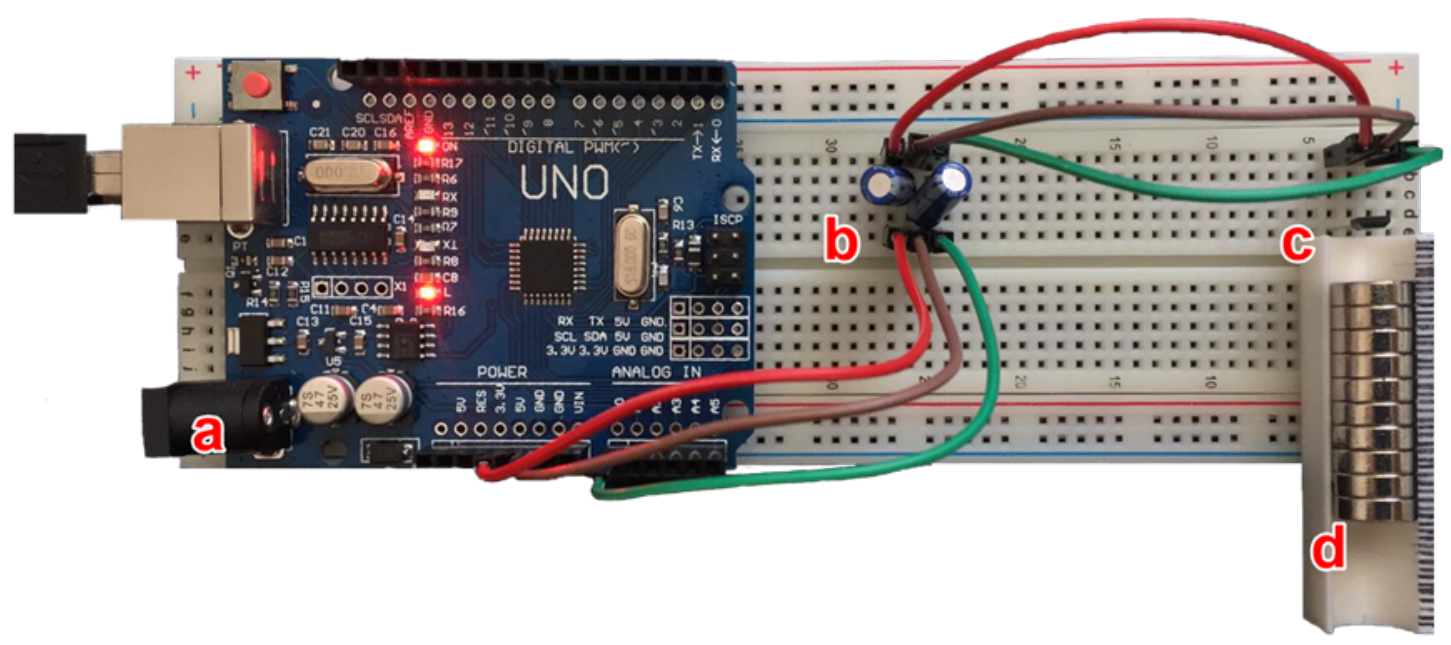

Figure 6. Arduino UNO R3 (a), capacitors (b), hall effect sensor (c), and 10 magnets (d). 


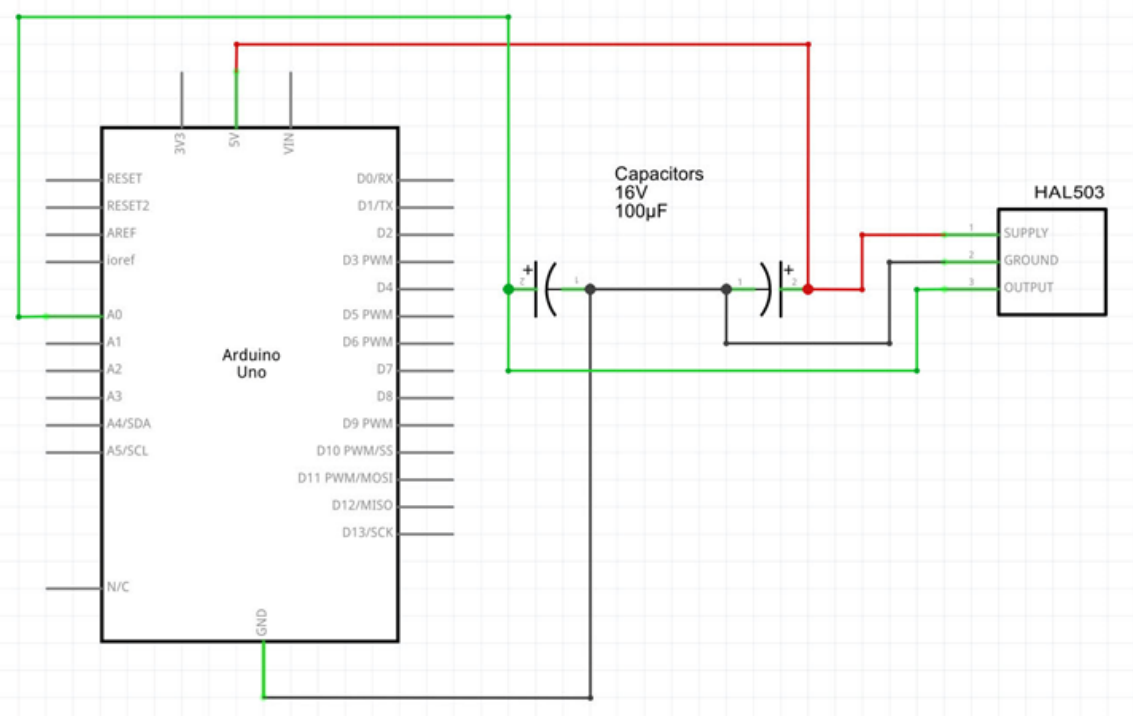

Figure 7. Schematics diagram of the magnetic field measurement system.

\subsection{Methods}

\subsubsection{Magnetic Field Measurement}

It is used to calculate the magnetic field force in gauss, near a disc or cylinder-shaped neodymium magnet in the magnetic field calculation. Important points in the magnetic field calculation;

1. Magnet material,

2. Remanence $(\mathrm{Br})$,

3. Magnet shape,

4. Diameter,

5. Thickness (the direction of magnetization).
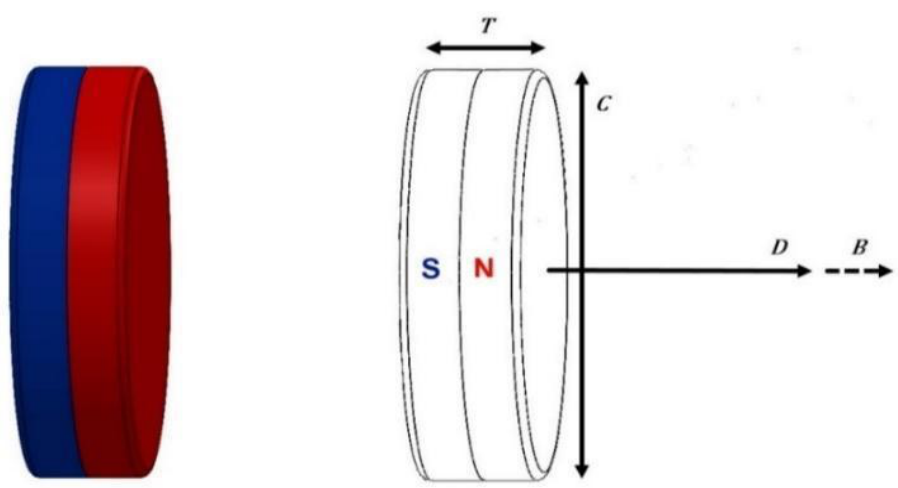

Figure 8. Size and distance parameters for cylinder-shaped magnets (Thickness T, Diameters C, Distance D, Magnetic field B).

The Magnetic Field (gauss) can be evaluated at different levels, in the research, diameter, thickness, and distance values was entered on the K\&J Magnetics site to evaluate the magnetic field values online (Anonymous, 2021). The magnetic field calculation is generally done the following formula: 
$B=\frac{B_{r}}{2}\left(\frac{T+x}{\sqrt{R^{2}+(T+x)^{2}}}-\frac{x}{\sqrt{R^{2}+x^{2}}}\right)$

In this formula (Coramık and Ege, 2018);

B: Magnetic field $(10$ Gauss $(\mathrm{G})=1$ Militesla $(\mathrm{mT}))$

$\mathrm{X}$ : Distance,

$\mathrm{R}$ : Magnet diameter,

T: Thickness,

$B_{r}$ : Remanence (Figure 8).

\subsubsection{LabVIEW based Gaussmeter Software}

There are a lot of scientific softwares like MATLAB, L takes, etc. Between these platforms, LabVIEW is a useful development platform. Because of this reason, LabVIEW platform was chosen for the Arduino-based low-cost gaussmeter software development platform. The connection between the Arduino and LabVIEW platform was made with the help of LINX firmware. Arduino was connected to the computer by using a USB port. Results of this connection Windows operating system created a com port for precise communication. This part can be selected by using the front panel of the LabVIEW gaussmeter (Figure 9). The Hall-effect sensor can be connected with different analog channels of the development board because the board has different channels for the connection of different sensors. As a result of this condition, channel selection properties were added to the front panel of the Arduino gaussmeter. A chart was placed in the front panel to see the differences of gauss value during one minute period. For the calibration of the low-cost gaussmeter control, input was also added. Instant loop rate and gauss values can be seen as decimal numbers from the front panel. Also, a gauge tool was placed to better understand the gauss differences visually. The measurement process can be stopped by using the stop button on the front panel of the developed software.

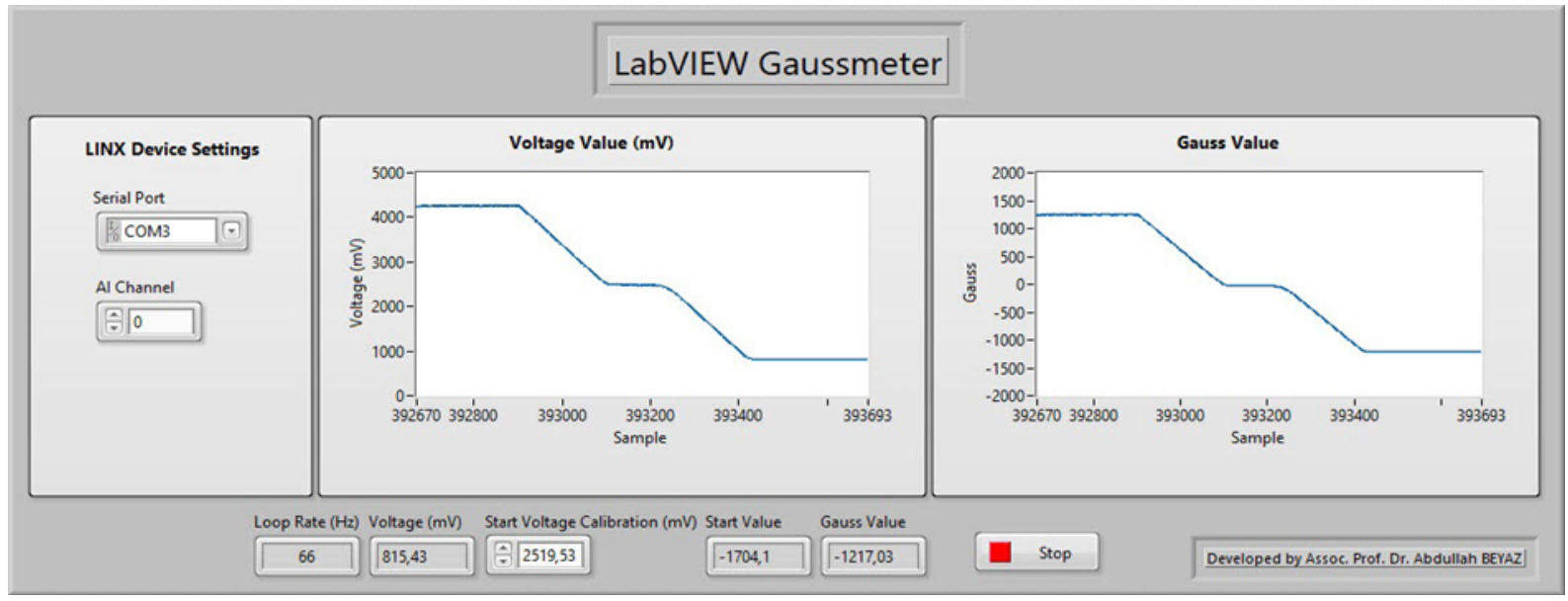

Figure 9. The front panel with measurement LabVIEW Gaussmeter.

Arduino has six ADC channels that any one or all of them can be used as inputs for analog voltage. The Arduino UNO R3 ADC has a 10-bit resolution, so it means that the integer values change between 0 to 1023. This also means that it will map input voltages between 0 and 5 volts into integer values between 0 and 1023 (Khan et al., 2017). For every integer value corresponding to $5 / 1024=4.9$ $\mathrm{mV}(0.0049 \mathrm{~V})$ per unit. The default reference if 5 volts and resolution are 10 bit we get $5 / 1024=4.9$ $\mathrm{mV}$ for every one increment that is counted. The sensor calibration was done by using an online theoric gauss calculator for getting the gauss values according to the type of grade, diameter, and thickness of the magnet and distance. Then the 0 gauss output of the sensor is $2500 \mathrm{mV}$. To get $2500 \mathrm{mV}$ output also we need to subtract the $2519,53 \mathrm{mV}$ value first to hold a $0 \mathrm{~V}$ read at the 0 Gauss field in the block diagram of the developed software (Figure 10). 


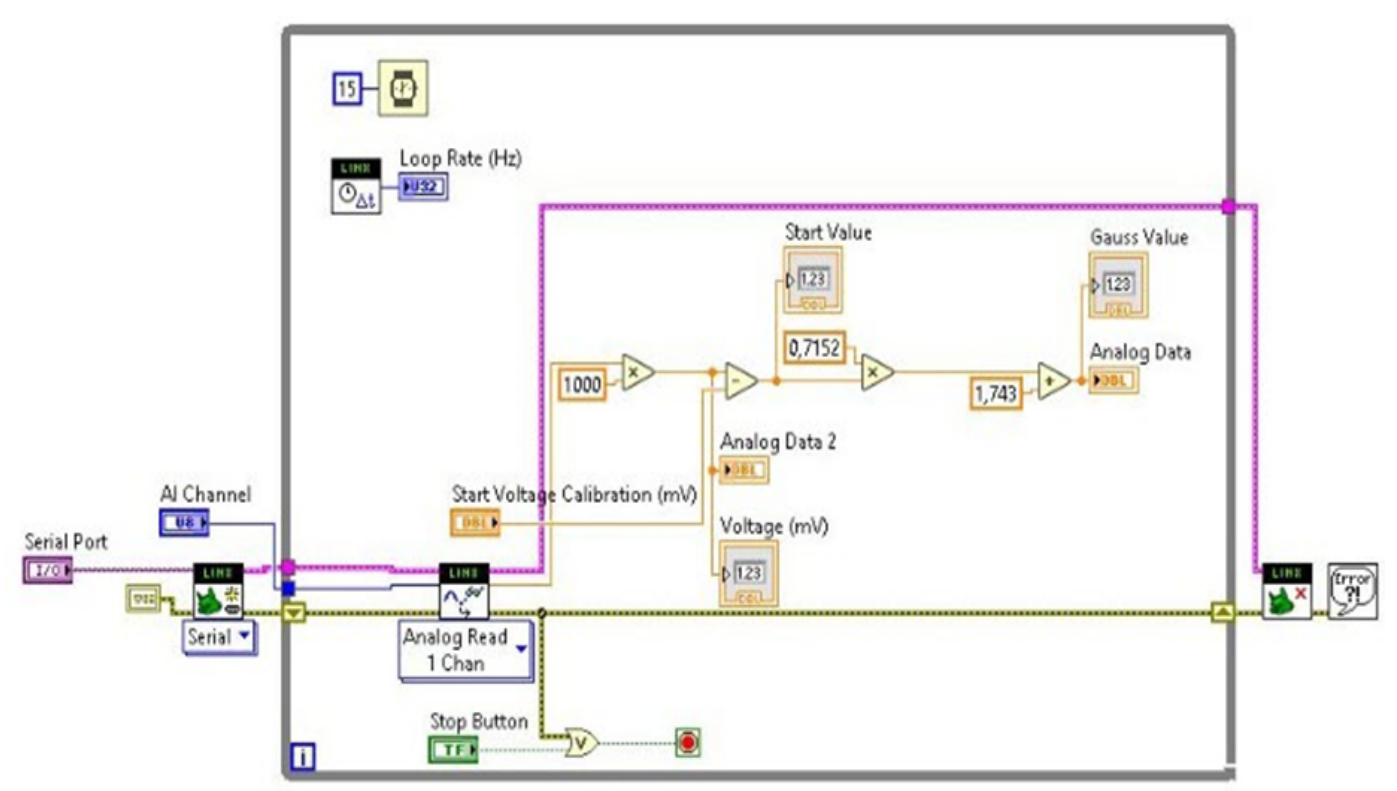

Figure 10. Block diagram of LabVIEW Gaussmeter.

\section{Result and Discussion}

The regression coefficient and estimation equation for Calculated Gauss Value - LabVIEW Gauss Value (Gauss) can be seen in Figure 11.

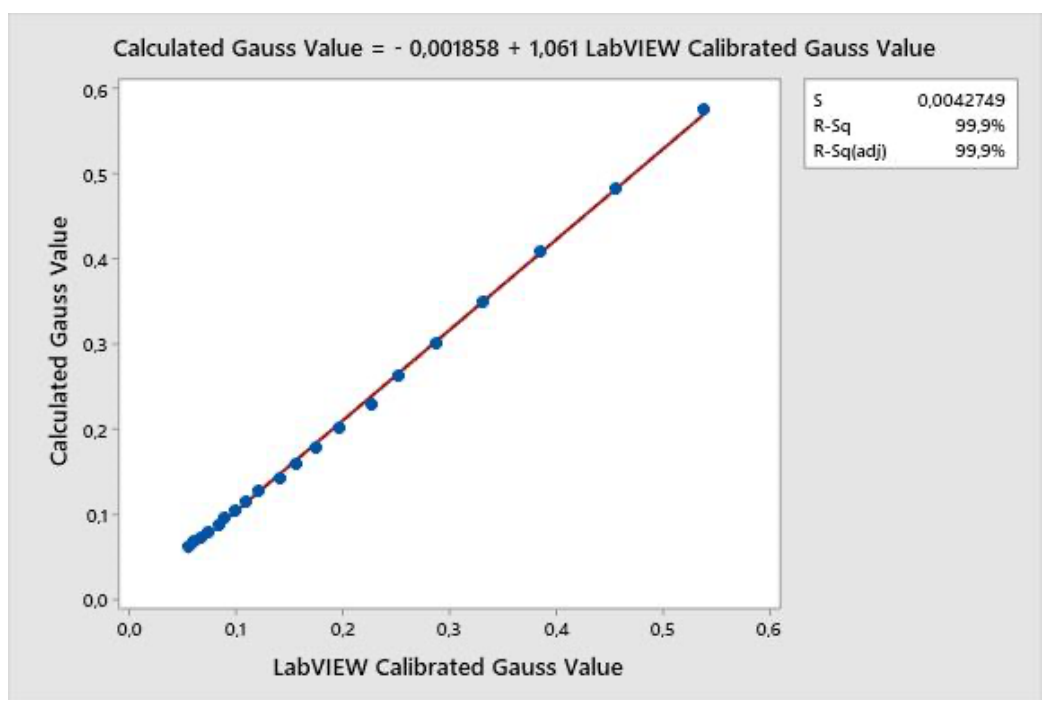

Figure 11. Calculated Gauss Value - LabVIEW Calibrated Gauss Value regression and estimation equation.

Also, regression coefficient and estimation equation for Calculated Gauss Value - LabVIEW Calibrated Gauss Value (Gauss) can be seen in Figure 12. 


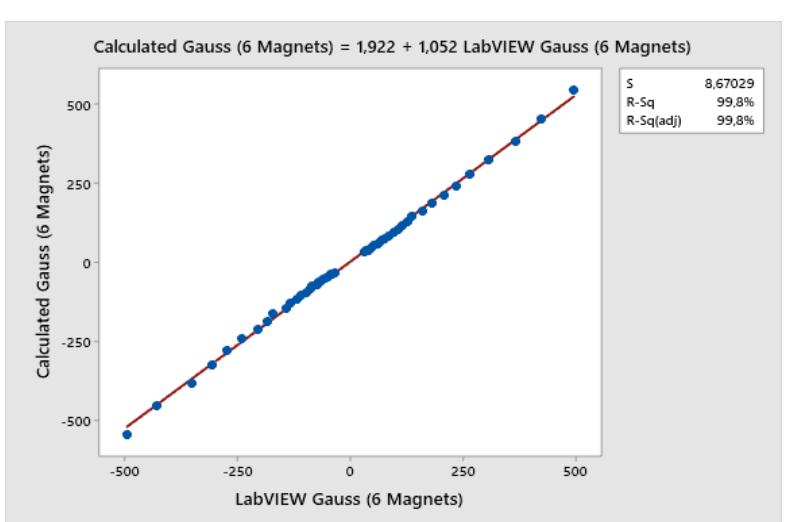

(a)

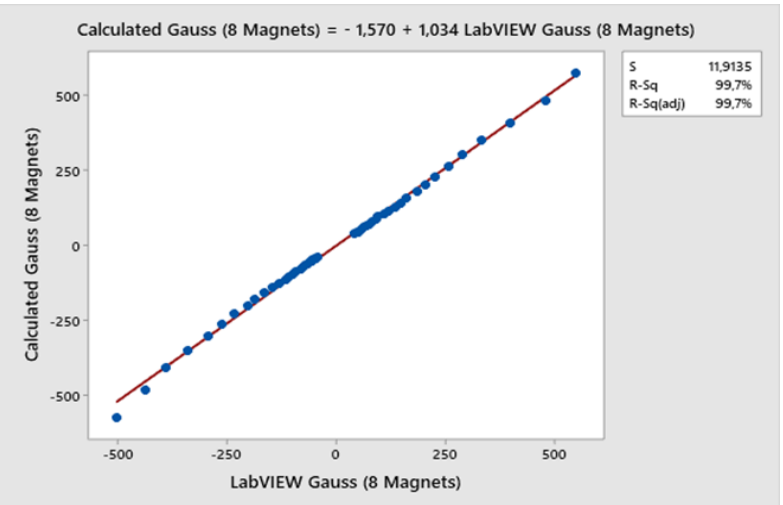

(b)

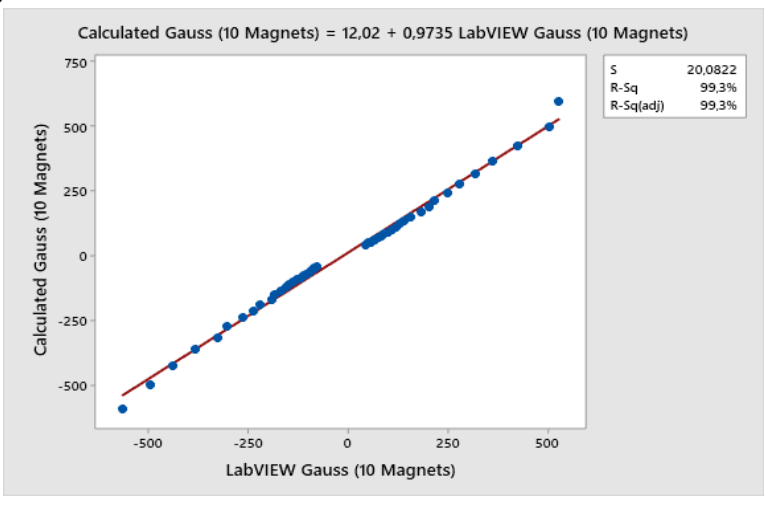

(c)

Figure 12. 6 Magnets (a), 8 Magnets (b), and 10 Magnets (c) Calculated Gauss Value - LabVIEW Gauss (Gauss) regressions and estimation equations.

Haned and Missous (2003) express that the Hall effect sensor measures efficiently at $1 \mu \mathrm{T}$ using $\mathrm{DC}$ techniques and $100 \mathrm{nT}$ using $\mathrm{AC}$ techniques at low-level magnetic fields. Also, the measurement results show that the LabVIEW-based low-cost gaussmeter which was developed with the help of LabVIEW software is working efficiently. The measurement system has the capability of calibration for different industrial gaussmeter corrections. It means that the system can be easily calibrated by using the calibration control part of the front panel. According to Puaypung and Rakkapao, (2018) magnetic field measurement research measurements can display about a $0.6 \%$ difference between the experimental and theoretical magnitudes of the magnetic fields. In their experiment, they simply obtained a linear relationship between the magnetic field (B) and the applied current (I) as B $=33.24 \mathrm{I}$ $\mathrm{mT}$ with $\mathrm{R}^{2}=0.99$. Also, Oy et al. (2015) claim that the gaussmeter which is developed by them can be used more economically than if the measurement can be made between $+1000 \mathrm{G}(0.1 \mathrm{~T})$ and $-1000 \mathrm{G}(-$ $0.1 \mathrm{~T})$. In their research, their gaussmeter gave $\% 100$ regression with a limited number of measurements (9 readings) at the measurements that had been done between $+1000 \mathrm{G}(0.1 \mathrm{~T})$ and $-1000 \mathrm{G}(-0.1 \mathrm{~T})$. On the contrary of the research of Oy et al. (2015), in this research, the post-calibration regression calculations of the values taken from three different thickness neodymium $(\mathrm{NdFeB})$ magnets were $99.8 \%$ for 6 magnets, $99.7 \%$ for 8 magnets, and $99.3 \%$ for 10 magnets from 50 readings for each magnet group, totally 150 readings were done. In the measurements made with 3 different thickness magnets for the calibrated device, it was observed that the gauss measurement in the LabVIEW program operated with an average accuracy of $99.6 \%$ between $-500 \mathrm{G}(-50 \mathrm{mT})$ and $+500 \mathrm{G}(+50 \mathrm{mT})$.

\section{Conclusion}

The developed system has been provided to be efficient and economical in laboratory applications to be performed by students, scientists, and experts, compared with the gauss meters that are more expensive and wide measurement range. Using this system, which is easy to use and measure the data and also calibrate, it has been ensured that measurements for various agricultural activities can 
be made accurately and effectively. Also, the choice of ADC is important in terms of the precision of the measurements. Therefore, its performance has been taken into consideration when selecting ADC (Analog Digital Converter). Measurement accuracy can be increased by using higher-resolution ADC and more sensitive sensors (Oy et al., 2015). Since the developed system works through a computer, it works properly in indoor cultivation, factories, and industrial built-in spaces. A laptop is required for instant measurements of the system in agricultural land and breeding places. In order to provide flexibility to the user in terms of mobility and portability, the system can be re-coded for mobile use and used with instant telephone measurements in the field.

\section{References}

Ahmadi, M., Bolandnazar, S., Panahandeh, J., \& Masouleh, S. S. S. (2020). The Effects of Magnetic Compounds on Growth and Yield of Cucumber under Greenhouse Conditions. Yuzuncu Yil University Journal of Agricultural Sciences, 30 (Additional issue), 890-897.

Amaya, J. M., Carbonell, M. V., Martinez, E., \& Raya, A. (1996). Effects of stationary magnetic fields on germination and growth of seeds. Hortic. Abst., 68, 1363.

Anonymous, (2018). Capacitor, Web Site: https://en.wikipedia.org/wiki/Capacitor, (accessed April 25, 2021).

Anonymous, (2021). The Original K\&J Magnet Calculator, Pull Force. Web Site: https://www.kjmagnetics.com/calculator.asp, (accessed April 25, 2021).

Badaroglu, M., Decabooter, G., Laulanet, F., \& Charlier, O. (2008). Calibration of integrated CMOS hall sensors using coil-on-chip in ATE environment. In Proceedings of the conference on Design, automation and test in Europe, 873-878.

Belyavskaya, N. A. (2001). Ultrastructure and calcium balance in meristem cells of pea roots exposed to extremely low magnetic fields. Advances in Space Research, 28(4), 645-650.

Belyavskaya, N. A. (2004). Biological effects due to weak magnetic field on plants. Advances in space Research, 34(7), 1566-1574.

Blagojevic, M., De Venuto, D., \& Kayal, M. (2004). SOI Hall sensor based solid state meter for power and energy measurements. IEEE-In Sensors Journal, 1040-1043.

Can, H., \& Topal, U. (2015). Design of ring core fluxgate magnetometer as attitude control sensor for low and high orbit satellites. Journal of Superconductivity and Novel Magnetism, 28(3), 10931096.

Coramı, M., \& Ege, Y. (2018). Can the Smartphones and Applications be Used in the Measurement of Magnetic Field Strength? International Necatibey Educational and Social Sciences Research Congress.

D'Ausilio, A. (2012). Arduino: A low-cost multipurpose lab equipment. Behavior research methods, 44(2), 305-313.

Danilov, V., Bas, T., Eltez, M., \& Rizakulyeva, A. (1993). Artificial magnetic field effect on yield and quality of tomatoes. In II Symposium on Protected Cultivation of Solanacea in Mild Winter Climates, 366, 279-286.

Duarte Diaz, C. E., Riquenes, J. A., Sotolongo, B., Portuondo, M. A., Quintana, E. O., \& Perez, R. (1997). Effects of magnetic treatment of irrigation water on the tomato crop. Hortic. Abst., 69, 494.

Esitken, A., \& Turan, M. (2004). Alternating magnetic field effects on yield and plant nutrient element composition of strawberry (Fragaria $x$ ananassa cv. Camarosa). Acta Agriculturae Scandinavica, Section B-Soil \& Plant Science, 54(3), 135-139.

Goldberg, C., \& Davis, R. E. (1954). New galvanomagnetic effect. Physical Review 94(5), 1121.

Hall, E. H. (1879). On a new action of the magnet on electric currents. American Journal of Mathematics, 2(3), 287-292.

Haned, N., \& Missous, M. (2003). Nano-tesla magnetic field magnetometry using an InGaAs-AlGaAsGaAs 2DEG Hall sensor. Sensors and Actuators A: Physical, 102(3), 216-222.

Khan, A. M., Lande, P. L., Baderao, S. A., \& Ali, R. I. (2017). Arduino-UNO based Magnetic Field Strength Measurement. IJIRST -International Journal for Innovative Research in Science \& Technology, (4-7), 46-49. 
Lin, I. J., \& Yotvat, J. (1990). Exposure of irrigation and drinking water to a magnetic field with controlled power and direction. Journal of magnetism and magnetic materials, 83(1-3), 525526.

Logofatu, M., Munteanu, I., Logofatu, B., \& Lazarescu, M. F. (1997). Magnetic Field Sensor With Linear Response. Sensor and Actuators A: Physical, 59(1-3), 149-152.

Morvic, M., \& Betko, J. (2005). Planar Hall effect in Hall sensors made from InP/InGaAs heterostructure. Sensors and Actuators A: Physical, 120(1), 130-133.

Muraji, M., Asai, T., \& Tatebe, W. (1998). Primary root growth rate of Zea mays seedlings grown in an alternating magnetic field of different frequencies. Bioelectrochemistry and Bioenergetics, 44(2), 271-273.

Muraji, M., Nishimura, M., Tatebe, W., \& Fujii, T. (1992). Effect of alternating magnetic field on the growth of the primary root of corn. IEEE Transactions on magnetics, 28(4), 1996-2000.

Murphy, J. (1999). Gaussmeter applications. In Proceedings: IEEE-Electrical Insulation Conference and Electrical Manufacturing and Coil Winding Conference, 573-576.

Nowicki, M., \& Szewczyk, R. (2013). Ferromagnetic objects magnetovision detection system. Materials, 6(12), 5593-5601.

Nowicki, M., \& Szewczyk, R. (2019). Determination of the Location and Magnetic Moment of Ferromagnetic Objects Based on the Analysis of Magnetovision Measurements. Sensors, 19(2), 337.

Oy, S. A., Demirtas, M., \& Aydin, O. (2015). The Desıgn and Applicatıon Of Gaussmeter with Hall Effect Sensor for Magnet1c Field Measurements. Afyon Kocatepe University Journal of Science and Engineering, 15(3), 8-12.

Podlesny, J., Pietruszewski, S., \& Podlesna, A. (2004). Efficiency of the magnetic treatment of broad bean seeds cultivated under experimental plot conditions. International Agrophysics, 18(1).

Popovic, R. S. (1991). Hall Effect Devices, Adam Hilger. Bristol, Philadelphia and New York.

Popovic, R. S., Schott, C., Shibasaki, I., Biard, J. M., \& Foster, R.B. (2001). Hall-effect magnetic sensors. Magnetic Sensors and Magnetometers. Norwell, MA: Artech House.

Prasad, G., Agnihotri, K., \& Tathagat, K. (2014). Arduino Based Gauss Meter. International Journal Of Engineering Research \& Management Technology, (1-2), 291-297, 2348-4039.

Puaypung, W., \& Rakkapao, S. (2018). A low-cost Arduino microcontroller for measuring magnetic fields in a solenoid. In Journal of Physics: Conference Series, 1144-1.

Randjelovic, Z., Pauchard, A., Haddab, Y. \& Popovic, R. S. (1999). A Non-Plate Hall Sensor. Sensor and Actuators A: Physical, 76, 149-152.

Ripka, P., \& Janosek, M. (2010). Advances in magnetic field sensors. IEEE-In Sensors Journal, 10(6), 1108-1116.

Schott, C., Besse, P. A., \& Popovic, R. S. (2000). Planar Hall effect in the vertical Hall sensor. Sensors and Actuators A: Physical, 85(1-3), 111-115.

Seely, E. S. (1997). Magnet measuring for the user. In Proceedings: IEEE-Electrical Insulation Conference and Electrical Manufacturing and Coil Winding Conference, 437-440.

Turker, M., Temirci, C., Battal, P., \& Erez, M. E. (2007). The effects of an artificial and static magnetic field on plant growth, chlorophyll and phytohormone levels in maize and sunflower plants. Phyton Ann. Rei Bot, 46, 271-284. 